\title{
VIVER SAUDÁVEL: SIGNIFICADO ATRIBUÍDO PELA EQUIPE DE SAÚDE E LIIDERES COMUNITÁRIOS
}

\author{
HEALTHY LIVING: MEANING ASSIGNED BY THE HEALTHCARE \\ TEAM AND COMMUNITY LEADERS
}

\author{
Elizane Medianeira Gomes Pires ${ }^{1 *}$, Talita Portela Cassola ${ }^{2 *}$, Dirce Stein Backes ${ }^{3 *}$, \\ Silomar Ilha ${ }^{4 * *}$, Marielle Kulakowski Obem ${ }^{5 *}$, Matheus Viero ${ }^{6^{*}}$ \\ 17elizanegomespires@hotmail.com, 2talita_cassola@hotmail.com, 33backesdirce@ig.com.br, \\ ${ }^{4}$ silo_sm@hotmail.com, ${ }^{5}$ mary_kowski@hotmail.com, ${ }^{6}$ enf.matheusviero@gmail.com \\ *Centro Universitário Franciscano UNIFRA \\ **Universidade Federal de Rio Grande-PPGEnf/FURG
}

Data de entrada do artigo: 29/07/2013

Data de aceite do artigo: 05/11/2013

\section{RESUMO}

Objetivo: Conhecer o significado do viver saudável para profissionais que compóem uma equipe de "Estratégia Saúde da Família" e para líderes comunitários, bem como identificar elementos que contribuam para o viver saudável. Metodologia: Pesquisa exploratória, qualitativa realizada com 9 profissionais da equipe de saúde da família e 2 líderes de uma comunidade socialmente vulnerável, localizada na região central do Rio Grande do Sul. Os dados foram coletados por meio de entrevista semiestruturada, entre os meses de janeiro e março de 2012. Resultados: Os dados analisados com base nos pressupostos de Bardin resultaram nas seguintes categorias: Significando o viver saudável, Interveniências favoráveis e desfavoráveis da Estratégia de Saúde da Família e A interferência político-partidária no processo do viver saudável. Consideraçóes Finais: Conclui-se que o significado do viver saudável evidenciado neste estudo está sintonizado com os princípios da OMS, a Carta de Ottawa e com a VIII Conferência Nacional de Saúde, os quais remetem aos direitos, deveres e responsabilidades dos principais atores sociais comprometidos com o processo saúde/doença.

Palavras-chave: Pesquisa em Enfermagem; enfermagem em saúde comunitária; programa saúde da família; promoção da saúde.

\section{ABSTRACT}

Objective: To know what is the meaning of a healthy living for professionals who are part of the Family Health Strategy and for community leaders, as well as identify elements that contribute to a healthy living. Methodology: This exploratory and qualitative research held with 9 professionals of the Family Health Team and 2 community leaders of a community socially vulnerable, located in the central region of Rio Grande do Sul, Brazil. The data were collected through semi-structured interviews, between January and March 2012. Results: The data analyzed based on Bardin's assumptions resulted in the following categories: Signifying healthy living, Favorable and Unfavorable Interveniences of the Family Health Strategy and The political interference in the process of a healthy living. Conclusions: The significance of a healthy living evidenced in this study is in tune with the principles of the World Health Organization (WHO), the Ottawa Charter and the VIII National Health Conference, which refer to the rights, duties and responsibilities of the main social actors committed to the health/disease process.

Keywords: Nursing research; community health nursing; family health program; health promotion. 


\section{Introdução}

Promover a saúde tem sido tema de muitas discussóes de âmbito científico, desde a criação do novo conceito de saúde pela Organização Mundial da Saúde (OMS) e das quatro Conferências Internacionais sobre a promoção da saúde. Nessa perspectiva, conforme o que relata a Carta de Ottawa, e a partir de discussóes da VIII Conferência Nacional de Saúde realizada no Brasil em 1986, a promoçáo da saúde se dá por meio do viver saudável com o lazer, acesso aos serviços públicos, a adoçáo de hábitos de vida saudáveis, o bem-estar consigo mesmo, o viver bem em família, sociedade, entre ou$\operatorname{tros}^{1}$.O viver saudável do ser humano pode ser apreendido como um processo sistêmico, dinamizado a partir das relaçōes, interações e associaçoos entre os diferentes atores e setores sociais. As práticas do viver saudável de indivíduos, famílias e comunidades vulneráveis requerem atitudes proativas e empreendedoras em busca de estratégias baseadas nas necessidades, facilidades, potencialidades e fragilidades ${ }^{2}$. A situação de vulnerabilidade social ocorre quando indivíduos são expostos a fatores de risco que podem ser pessoais, sociais e ambientais, e podem partir de uma pessoa para uma família e/ou para uma comunidade, na qual o indivíduo integrado ao sistema não consegue processar sua auto-organização para o viver saudável ${ }^{3}$.

Promover uma vida saudável em comunidades vulneráveis como um fenômeno singular e multidimensional, que requer, da mesma forma, estratégias de intervenção também singulares, constitui-se um desafio para os profissionais de saúde. Nesse sentido, a atuação estratégica dos profissionais comprometidos com a saúde requer o desenvolvimento de oportunidades que ampliem as possibilidades interativas e associativas entre os diferentes atores e setores, a fim de apreender a saúde como um fenômeno amplo, complexo e singular, interligado aos diferentes sistemas sociais que visam à promoção de uma vida saudável ${ }^{4}$.

A Estratégia Saúde da Família (ESF), nesse contexto, está inserida e deve atuar na promoção do viver saudável, por meio de açóes que desenvolvam a autonomia e a auto-organização dos indivíduos e famílias. Nesse processo encontram-se os Agentes Comunitários de Saúde (ACS), que têm sido apontados na literatura como os principais responsáveis pelo levantamento das necessidades de saúde, por meio da visita domiciliar e também pelo acompanhamento da carteira de saúde e do cartão da famílias.

Neste cenário, o enfermeiro tem a possibilidade de atuar como mediador entre famílias e políticas públicas de saúde. Por sua formação generalista e sistêmica para o cuidado dos indivíduos, famílias e comunidades, de modo integral, ele possui condiçóes de exercer a liderança de maneira proativa, em um processo dinâmico de construção do viver saudável e da auto-organização familiar. Assim, o enfermeiro deve elaborar estratégias criativas e inovadoras que contribuam para a promoção do viver saudável dos indivíduos, da família e da comunidade em situação de vulnerabilidade, principalmente, na consolidação da Estratégia de Saúde da Família $(\mathrm{ESF})^{6}$.

Diante da necessidade de se desenvolver atitudes proativas e empreendedoras que possibilitem a elaboração de estratégias que potencializem a atuação da equipe da ESF e das lideranças, para a promoção do viver saudável de famílias socialmente vulneráveis, questiona-se: o que significa o viver saudável para os profissionais da equipe de saúde da família e lideres comunitários? Nessa direção, o estudo teve por objetivo conhecer o significado do viver saudável para profissionais de saúde de uma Estratégia de Saúde da Família e líderes comunitários, e também identificar elementos que contribuem para intervir no processo do viver saudável.

\section{Metodologia}

Trata-se de um estudo exploratório descritivo de caráter qualitativo, vinculado ao projeto "A promoção do viver saudável de famílias socialmente vulneráveis, pelo desenvolvimento de práticas sociais empreendedoras", financiado pela Fundação de Apoio à Pesquisa do Rio Grande do Sul (FAPERGS).

A pesquisa foi realizada em uma comunidade localizada na região central do estado do Rio Grande do Sul. A comunidade em questáo é constituída por $25 \mathrm{mil}$ habitantes, composta em grande parte por famílias em condiçôes socialmente vulneráveis.

Como critério de inclusão estabeleceu-se: ser profissional de saúde da Estratégia de Saúde da Família e ser membro líder da comunidade onde se realizou o estudo. Os participantes foram selecionados a partir de um convite formal, sendo que todos os profissionais da ESF aceitaram o convite: um enfermeiro, um técnico em enfermagem, um médico e seis agentes comunitários de saúde. Dos cinco líderes comunitários contatados, apenas dois aceitaram participar do estudo, formando o corpus deste estudo 11 sujeitos.

Os dados foram coletados por meio de entrevista semiestruturada, realizada individualmente, por meio das seguintes questôes norteadoras: o que significa o viver saudável para você? A partir do seu ponto de vista, quais são os elementos que contribuem para o viver saudável da família e da comunidade?

As entrevistas foram realizadas entre os meses de janeiro e março de 2012, na unidade local da ESF, em dias e horários previamente agendados. Foram gravadas 
e, a seguir, analisadas com base na técnica de análise de conteúdo ${ }^{7}$, que é divida em três momentos: o primeiro leva em conta a frequência, com a identificação das principais percepçóes dos sujeitos entrevistados; o segundo analisa o conteúdo e identifica as categorias que emergiram a partir dos dados coletados; e o terceiro refere-se à interpretaçấo das categorias, e compreende suas significaçóes.

Foram considerados os preceitos éticos e legais que envolvem a pesquisa com seres humanos, conforme a resolução 196/96 do Ministério da Saúde ${ }^{8}$. Manteve-se o anonimato dos depoentes e eles foram identificados pela letra "P" - referente a participante -, seguida de um algarismo numérico, conforme a ordem de entrevista (P1, P2... P11). Em cumprimento das normas da resolução, o projeto de pesquisa foi aprovado pelo Comitê de Ética em Pesquisa do Centro Universitário Franciscano (Unifra), e registrado no Conep, sob o número 1246.

\section{Resultados}

Os dados organizados e analisados resultaram em três categorias: Significando o viver saudável; Interveniências favoráveis e desfavoráveis da ESF; A interferência político-partidária no processo de viver saudável.

\section{Viver saudável}

A categoria "Significando o viver saudável" está associada a vários fatores determinantes, como ter uma boa alimentação, ter paz e harmonia no lar, ter acesso facilitado e de qualidade aos serviços de saúde, entre outros. Para a enfermagem, o viver saudável está associado ao dia a dia familiar em sua dinâmica e sua relação entre ter saúde, condições adequadas de moradia, alimentação, lazer e harmonia.

Viver saudável é tu ter todas aquelas condiçóes assim: ter saúde, casa, moradia, comida, paz, tranquilidade, saúde, ver os filhos, bem... Não adianta vir aqui, a gente orientar e orientar, e a criatura ir ali no barraquinho dele e não ter nada. Tem uma área verde ali que não tem nada, fica todo mundo dentro de casa e náo tem uma pracinha pras crianças brincar (P7).

Para o médico da saúde da família, o viver saudável está associado à adoção de hábitos de saudáveis, por meio da prevenção de doenças, da prática regular de exercícios físicos, de uma alimentação saudável, como relata a fala:

O viver saudável é significado através de uma vida saudável, de uma alimentação saudável, da realização de exercícios físicos, da manutenção da saúde. Isso se dá, como posso dizer... O cidadão tem que estar mais atento, procurar sua saúde, se manter atualizado acerca de seu estado de saúde, deve procurar atendimento. Muitas vezes as pessoas só procuram atendimento quando o problema já está muito avançado e, aí, pra correr atrás nem sempre é fácil, então a população deve se manter atenta pra viver mais saudável (P 8).

Já, para os ACS, o viver saudável está relacionado à qualidade de vida, sendo a saúde o fator determinante associado a ter atendimento de uma equipe de saúde qualificada e atuante. É ter saneamento básico, alimentação adequada, moradia digna, acesso ao ambiente escolar, à prática de exercícios físicos, áreas de lazer, entre outros. Como descreve as falas: "Olha, eu acho que viver saudável, pra nós aqui, é o nosso saneamento básico “(P2). "É ter condiçôes de acessar uma escola [...] é ter áreas de lazer e um ambiente saudável” (P3).

É qualidade de vida. O que engloba essa qualidade de vida? Alimentação saudável, saúde, principalmente ter saúde, porque a comunidade não tem como viver bem se não tiver saúde. Então tudo é uma engrenagem, se tu não tiver um médico na unidade, não vai ter qualidade de vida na comunidade. Hoje, graças a Deus, nós temos a nossa unidade de saúde completa (P5).

Na visão dos líderes comunitários, o viver saudável significa ser cidadão. É exigir os direitos, ter os benefícios garantidos pelo governo, emprego e renda, saúde, acesso aos serviços de saúde, viver em um ambiente saudável, conforme as falas:

Viver saudável é ter saúde, uma boa alimentação, garantir os seus direitos, ter emprego, ter todas essas bolsas governamentais pra sobrevivência, acho que todos esses fatores e um ambiente com ar puro pra respirar... Sei que não é fácil nos dias de hoje ter um ar puro. É mais ou menos por aí, ter condições melhores de vida para viver saudável (P10).

Ah... viver saudável é assim oh... Como eu vou te explicar, ter uma boa saúde, né. Nós temos um posto de saúde pra que as pessoas adoeçam e tenham como ser atendidas naquela hora, naquele momento (P11).

Percebe-se que o viver saudável tem diferentes significados. Considerando a atuação e envolvimento na dinâmica da comunidade, a enfermagem está voltada para o processo familiar e suas implicaçóes. Já os ACS percebem com maior clareza as fragilidades e necessidades da comunidade, e os líderes têm uma concepção mais política, voltada para as dificuldades das famílias. 


\section{Influências positivas e negativas no viver saudável}

A categoria foi delimitada a partir de elementos que interferem de maneira favorável ou desfavorável no processo de viver saudável, sejam elas: vínculo profissional/ usuário, comprometimento e envolvimento com as reais necessidades individuais e coletivas, e busca de estratégias. Os participantes apresentaram como condiçôes favoráveis para o processo de viver saudável: a atuação responsável do enfermeiro e a concepção ampliada de saúde com foco na prevenção de doenças e na promoção da saúde:

Para mim, como profissional que atua há muito tempo com os profissionais de saúde, eu vejo que aquele grande salário tinha que ser da enfermagem, porque quem faz a ação, a prevenção, tudo é a enfermagem [...] quando o enfermeiro é comprometido! (P3).

Antes, quando eu entrei, eles só iam quando estavam doentes. Hoje, com meu trabalho, consigo fazer eles virem antes. Por isso, quando eu entrei, achei "agente de saúde". Agora eu sei a grande importância que eu tenho na vida deles, a gente vai orientar, tem que ir a tal lugar, eles vão atrás, [...] por isso que eu acho que é muito importante o nosso trabalho com eles, porque a gente fez isso (P2).

A gente ficou uns dois anos praticamente só com a enfermeira, e assim, oh, ela moveu céus e terra, aquele trabalho preventivo, uma coisa assim fantástica! As pessoas tiveram mais saúde, tinham o grupo, se fosse ao posto era bem acolhida, aquele trabalho de prevenção englobou assim a comunidade que passou despercebido o médico (P6).

Quanto aos aspectos negativos, alguns participantes relataram que a atuação da equipe da ESF está interferindo de maneira desfavorável no processo do viver saudável, pela falta de ética entre os profissionais, e entre profissionais e usuários afetados pela acomodação e pela ausência de vínculo e interesse com a comunidade.

Acho que falta muito ética e profissionalismo, porque as pessoas vão e muitas vezes vêm tristes de lá, vão ser atendidas e não são bem recebidas, acabam ficando mais doentes ainda (P2).

[...] hoje ninguém consegue falar a mesma linguagem, aí dificulta, porque, numa equipe, se tu tens um projeto, um alvo pra atingir, todos têm que se ajudar. Mas a divisão em algum lugar existe, porque é mais fácil eu sentar, me acomodar e não brigar do que eu ir lá. Então assim, tudo isso tá gerando consequências ruins (P3).
[...] o agente de saúde, se ele é um bom agente, tem que promover autonomia, tem que ensinar a pessoa a pescar. É ela que tem que ir atrás, não levar; ficarem levando remédio como acontece, receita... Entâo, por isso, aqui eles têm divergências por causa disso, porque um faz e o outro não faz, e o que não faz é o que leva (P7).

Para alguns participantes, existem atitudes de dependência do usuário, na medida em que relatam que o usuário exige a marcação de consultas e exames, a distribuição de medicamentos e encaminhamento de problemas em geral, como revelam as falas a seguir: "Eu vejo uma grande maioria extremamente dependente do agente, por que ela tem na cabeça que, se tiver o agente, tudo é mais fácil (P3)". "Eles dependem muito do agente, eles querem que nós resolvamos. A nossa função é a promoção da saúde, não resolver os problemas de saúde. Se tá doente, eles querem que agente resolva (P5)".

Eles querem remédio, eles querem receitas, querem que tu leve em casa, e não é isso aí nosso trabalho. Eles têm que vir até o posto participar dos grupos, vir pegar medicação. Eles se tornam bem dependentes da gente, principalmente pra marcar consulta, e a gente tem que estar batendo na mesma tecla, a gente não pode marcar consulta (P6).

Percebe-se que o trabalho da equipe de saúde para a promoção do viver saudável está além da realização de açôes pontuais e lineares de saúde. Está atrelado à interação entre os membros da equipe, e entre a equipe e a comunidade, na qual a formação do vínculo se configura como elo principal na promoçáo da saúde, por meio de relaçóes baseadas na confiança e na ética do trabalho em equipe. No entanto, é necessário que a atuação do ACS seja repensada para que se torne alguém que favoreça a autonomia do usuário no processo de viver saudável.

\section{Interferência das políticas públicas no viver saudável}

A categoria faz referência às políticas públicas que interferem no viver saudável da comunidade. Os depoimentos demonstram sentimentos de insegurança frente às políticas públicas, que causam desinteresse $\mathrm{e}$ falta de participação da comunidade nas reuniôes de conselho locais, nas mobilizaçóes sociais da comunidade, entre outros - "Na verdade, nossa comunidade tem muito medo de ser usada politicamente; entáo eles não vão, sabe, eles não procuram os direitos deles (P1)". 
Pois é, a comunidade tem muito medo, porque tem muita politicagem. Então eu acho que a gente tirar isso da cabeça das pessoas e fazer com que a comunidade saiba que não tem a ver com politicagem, porque, quando faz uma reunião, falam: "Isso é politicagem". Então, vira e mexe, isso sempre acontece (P3).

Em outras circunstâncias foi relatado que as políticas públicas são usadas para garantir resultados em relação à manutenção de índices de saúde que garantem a credibilidade política.

$\mathrm{Na}$ verdade foi por causa dos índices, da extrema necessidade dos altos índices de mortalidade infantil, tudo de ruim era aqui. Acho que alguém lá olhou, sabe, pela vergonha de ter um programa e ter os índices altíssimos. Então foi uma questáo de índices, não foi pela comunidade. Acho que foi aquele despertar: estou perdendo dinheiro, pelo investimento (P3).

Nas falas, percebe-se que as políticas públicas interferem no viver saudável da comunidade. Assim, é necessário promover nos indivíduos uma visão crítica e proativa, para que saibam conviver e buscar seu viver saudável além das questôes políticas, usufruindo desse processo pela busca de conquistas que promovam a saúde.

\section{Discussão}

O viver saudável apresenta-se como um processo singular, complexo, dinâmico e circular, que interage com as dimensões individuais, familiares e comunitárias, associado a fatores internos e externos, tais como: o bem-estar individual, a saúde dos indivíduos, famílias e comunidade, o acesso aos serviços públicos de saúde, o lazer, a educação, o saneamento básico, entre outros.

Dessa forma, a promoção do viver saudável deve ser entendida como uma ação coletiva, objetivando a troca de experiências e a conscientização sobre o modo de vida, e assim potencializar açóes que promovam a mudança cultural ${ }^{9}$. A adoção de práticas educativas em saúde que atentem para a consciência cidadã e responsável gera potenciais de superação na comunidade, por meio de atitudes proativas e empreendedoras de estímulo à auto-organização, à autonomia e ao diálogo entre os indivíduos ${ }^{10}$.

A cooperação e a confiança transmitida pela equipe de saúde propiciam bases sólidas no processo de trabalho na ESF, para consolidação de estratégias que fortaleçam o processo de viver saudável. A interação entre a equipe de saúde e as lideranças comunitárias se constitui em um meio para a discussão do processo político e para emancipaçáo da comunidade ${ }^{11}$. Dessa forma organizada e criativa surgem espaços para o aprofundamento de discussóes sobre os significados de viver saudável baseados no acolhimento e na humanização do cuidado ${ }^{12}$.

Para tanto, a atuação da equipe de saúde, em especial da enfermagem, deve ser baseada em preceitos éticos e morais, de forma organizada e que crie uma interação criativa e orientada entre equipe e usuários ${ }^{13}$. Entendese que o cuidado de enfermagem é um fenômeno complexo e sistematizado por meio das múltiplas relaçóes, interaçóes e associaçôes sistêmicas, a fim de promover saúde de forma integral e articulada com tudo que o cerca ${ }^{4}$.Sendo assim, é preciso que a enfermagem conheça sua região e desempenhe um plano de ação apoiado no perfil das famílias e da comunidade, para que contribua com o sucesso da implementação do programa. Nesse sentido, os profissionais atuantes precisam desenvolver um olhar atento para as famílias e para o ambiente, podendo assim identificar fatores de risco e atuar de maneira eficaz ${ }^{14}$.O ACS é considerado o profissional mais próximo das famílias e da comunidade; executa encaminhamentos até a estratégia, efetua a prevenção e a promoção da saúde, orienta tratamentos e reabilitaçóes dos usuários, realiza mobilizaçôes na comunidade em busca de ambientes e condiçôes favoráveis à vida, entre outros ${ }^{15}$. No entanto, percebe-se que suas açóes na prática são baseadas em questôes pontuais, como a entrega de medicaçóes, envio de exames e agendamento de consultas ${ }^{16}$.

Os resultados positivos na ESF dependem tanto da equipe de saúde como da confiança dos usuários nos líderes comunitários e gestores públicos. A confiança dos usuários no poder público produz potenciais de ação através das lideranças comunitárias, as quais ganham força política para lutar pelas necessidades e reivindicaçóes da comunidade ${ }^{11}$. No entanto, é necessário ter cautela com a intervenção nesse processo, já que as intervenções políticas que pretendem suprir as necessidades, interesses e aspiraçōes sociais coletivas nem sempre são solicitadas ou aceitas pelos usuários, e afetam o viver saudável da comunidade. Nessa perspectiva, existem duas realidades que fazem referência ao caos social, designadas de ordem e desordem: a primeira é pobre e estática e reina nas grandes populaçôes; a segunda é indeterminada nas unidades elementares. Negar a desordem, nesse processo de viver e/ou sobreviver, significa negar a possibilidade da promoção de um viver saudável. Portanto, é necessário desconstruir visóes fragmentadas e mutiladoras, oriundas de mentes simplificadoras ${ }^{17}$.

Logo é necessário que a atuação do profissional de medicina seja mais ampla e sistêmica, com a finalidade de contemplar as fragilidades dos indivíduos, famílias e comunidade. Percebe-se que a atuação dos ACS, apesar de seus limitados recursos, evidencia uma concepção 
mais adequada e coerente, se comparada às necessidades da comunidade. $\mathrm{O}$ enfermeiro, pela sua habilidade proativa e inovadora, tem a possibilidade de auxiliar o processo auto-organizador, em relação a novos modos de promover o viver saudável.

Nesse contexto, a enfermagem realiza importantes tarefas na execução das ações, na consolidação de estratégias, no fortalecimento social, na criação de políticas públicas, na organização do serviço de saúde, além de sua competência técnica, ética e responsável, por meio dos princípios que norteiam o SUS, para a promoção do viver saudável e a autonomia dos indivíduos ${ }^{18}$.

\section{Considerações Finais}

O significado do viver saudável evidenciado neste estudo está sintonizado com os princípios da OMS, os pressupostos da Carta de Ottawa e as diretrizes da VIII Conferência Nacional de Saúde, os quais remetem aos direitos, deveres e responsabilidades dos profissionais de saúde, indivíduos, famílias e comunidade, bem como dos gestores públicos comprometidos com o processo saúde/doença. Tal compreensão induz a apreensão ampliada do viver saudável, entendida como um processo circular e dinâmico resultante da auto-organizaçáo e emancipação das famílias e da comunidade.

Conclui-se, em suma, que as intervençóes de enfermagem devem ser baseadas nos significados de viver saudável, que são subjetivos para cada comunidade. Para promover o viver saudável, nesse sentido, são necessárias ações que se concentrem na qualidade de vida dos indivíduos, para a conquista da comunidade, a busca de direitos e cumprimento de deveres como cidadãos, para o fortalecimento de atitudes políticas e participativas em comunidades vulneráveis, para a consolidação da ESF e da auto-organização, e o estímulo do protagonismo social dos indivíduos produtores de sua própria história.

\section{Referências}

1. Ministério da Saúde. Projeto promoção da saúde: cartas e declaraçôes das conferências internacionais de promoção da saúde. Brasília, 2001. Disponível em: <http://portal.saude. gov.br/portalArquivos/pdf/declaracoesecarta_portugues. pdf>

2. Erdmann AL, Backes MTS, Backes DS, Koerich MS, Baggio MA, Carvalho JN, et al. Gerenciando uma experiência investigativa na promoção do "viver saudável" em um projeto de inclusão social. Texto Contexto Enferm. 2009; 18(2):369-77.
3. Prati LE, Couto MCP, Koller SH. Famílias em vulnerabilidade social: rastreamento de termos utilizados por terapeutas de família. Psic: Teor e Pesq.[internet]. 2009; 25(3). Disponível em: <http://dx.doi.org/10.1590/ S0102-37722009000300014>

4. Gepeses. Grupo de Estudose Pesquisa em Empreendedorismo Social da Enfermagem e Saúde. Validaçáo de um conceito de enfermagem à luz da complexidade. Conceito discutido e validado no grupo de pesquisa, 2011.

5. Egry EY, et al. Instrumentos de avaliação de necessidades em saúde aplicáveis na estratégia de Saúde da Família. Rev Esc Enferm. USP. [internet]. 2009; 43(2):1181-1186. Disponível em: <http://www.scielo.br/scielo.php?script=sci_arttext\&pid=S0080-62342009000600006\&lng=en>

6. Backes DS, Erdmann AL, Büscher A. O cuidado de enfermagem como prática empreendedora: oportunidades e possibilidades. Acta Paul Enferm. [internet]. 2010; 23(3):341-347. Disponível em: <http:// www.scielo.br/scielo.php?script $=$ sci_arttext $\&$ pi $\mathrm{d}=$ S0103-21002010000300005\&lng=en>

7. Bardin L. Análise de conteúdo. 4a ed. Lisboa: Edições; 2009.

8. Ministério da Saúde. Conselho Nacional de Saúde. Resolução no 196. Diretrizes e normas técnicas regulamentadoras de pesquisa envolvendo seres humanos. Brasília; 1996.

9. Oliveira DL. A “nova” saúde pública e a promoção da saúde via educação: entre a tradição e a inovação. Rev Latino-am Enfermagem. [internet]. 2005; 13(3):423-31. Disponível em: <www.eerp.usp.br/rlae>

10. Santos MC, Siqueira HCH, Silva JRS. Saúde coletiva na perspectiva ecossistêmica: uma possibilidade de açóes do enfermeiro. Rev Gaúcha Enferm. [internet]. 2009; 30(4):750-4. Disponível em: <http://www.scielo.br/scielo. php?script=sci_arttext $\&$ pid=S1983-14472009000400023>

11. Valentim IVL, Kruel AJ. A importância da confiança interpessoal para a consolidação do Programa de Saúde da Família. Ciênc. Saúde Coletiva. [internet]. 2007; 12(3):777-788. Disponível em: <http:// www.scielosp.org/scielo.php?script $=$ sci_arttext $\&$ pi$\mathrm{d}=$ S1413-81232007000300028\&lng=en http://dx.doi. org/10.1590/S1413-81232007000300028>

12. Linard AG, Chaves ES, Rolim ILTP, Aguiar MIF. Princípios do Sistema Único de Saúde: compreensão dos enfermeiros da Estratégia de Saúde da Família. Rev Gaúcha Enferm. [internet]. 2011; 32(1):114-20. Disponível em: $<$ http://seer.ufrgs.br/RevistaGauchadeEnfermagem/article/ view/12333/12417>

13. Kraemer FZ, Duarte MLC, Kaiser DE. Autonomia e trabalho do enfermeiro. Rev Gaúcha Enferm. [internet]. 2011; 32(3):487-94. Disponível em: <http://seer.ufrgs.br/ RevistaGauchadeEnfermagem/article/view/13519/13930>

14. Figueiredo NM, et al . SUS e PSF para enfermagem: práticas para o cuidado em saúde coletiva. São Caetano do Sul, SP: Yendis; 2007. p. 157-188. 
15. Ministério da Saúde. O trabalho do Agente Comunitário de Saúde. Brasília, Secretaria de Políticas de Saúde, 2000. 119 p. Disponível em: <http://bvsms.saude.gov.br/bvs/publicacoes/cd09_05a.pdf>

16. Santos KT, Saliba NA, Moimaz SAS, Arcieri RM, Carvalho ML. Agente comunitário de saúde: perfil adequado a realidade do Programa Saúde da Família?. Ciênc. Saúde Coletiva. [internet]. 2011; 16(1). Disponível em: <http://www.scielo.br/scielo.
php?script=sci_arttext\&pid=S1413-81232011000700035>

17. Morin E. Os sete saberes necessários à educação do futuro. São Paulo: Cortez; Brasília, DF: Unesco, 2000

18. Bornstein VJ, Stotz EN. Concepts involved in the training and work processes of community healthcare agents: a bibliographical review. Ciênc. Saúde Coletiva. [internet]. 2008; 13(1):259-268. Disponível em: <http://dx.doi. org/10.1590/S1413-81232008000100029> 